\title{
Concentrated or Fragmented? The U.S. Market for Online Higher Education
}

\author{
John J. Cheslock ${ }^{1}$ D $\cdot$ Ozan Jaquette $^{2}$
}

Received: 1 August 2020 / Accepted: 21 May 2021 / Published online: 28 May 2021

(c) The Author(s), under exclusive licence to Springer Nature B.V. 2021

\begin{abstract}
As the financial challenges facing the U.S higher education industry mount, colleges and universities seek new activities that can improve their financial situation. Online education programs are often viewed as a promising option due to growing student interest and the substantial net revenue generated by early entrants that leveraged economies of scale and scope. The number of schools that can experience similar outcomes will depend upon whether the online market is primarily concentrated, with a small number of higher education institutions enrolling most students, rather than fragmented, with large numbers of institutions enrolling meaningful amounts of online students. We examine this topic by providing the first detailed study of market concentration in online education. We first introduce a theory from economics, Sutton's model of endogenous fixed costs, to the higher education literature to highlight key dynamics that shape concentration levels. Using institution-level enrollment data for the population of Title IV postsecondary institutions, we then empirically examine concentration levels in online education. We find that relative to in-person education, national online enrollment patterns are heavily concentrated. The online market has a distinctive structure, consisting of a small number of large national providers and a large number of small local providers. Online enrollment patterns became less concentrated between Fall 2012 and Fall 2018 due to major enrollment declines of large for-profit providers. Concentration levels, however, plateaued by the end of the period due to rapid enrollment growth at large national nonprofit providers.
\end{abstract}

Keywords Online education · Enrollment · University finances · Economics of education

John J. Cheslock

jjc36@psu.edu

Ozan Jaquette

ozanj@ucla.edu

1 Pennsylvania State University, University Park, USA

2 UCLA, Los Angeles, USA 


\section{Introduction}

U.S. colleges and universities face a range of financial challenges. In recent decades, organizational cost pressures steadily rose while the share of state funding devoted to higher education fell (Archibald \& Feldman, 2011, 2017; Kane et al., 2003). Higher education institutions responded to these trends by increasing net tuition revenue, but will find it difficult to produce further increases due to stagnating family income and concerns about student debt and access (Archibald \& Feldman, 2017). The coronavirus pandemic has made the situation even more challenging in the short run by threatening key existing revenue streams and increasing spending pressures in a number of areas (Smith, 2020). These revenue streams will face further challenges in the late 2020s when the "birth dearth" that followed the Great Recession leads to a reduction in high school graduates (Grawe, 2018).

Researchers and practitioners have provided advice to colleges and universities on how to navigate this difficult financial terrain (Christensen \& Eyring, 2011; Smith, 2020; Zemsky et al., 2005). A standard recommendation is for institutions to identify new programs in areas associated with rising demand by students and limited supply by other institutions. Online programs often receive a lot of attention due to growing student interest, especially from adult students. In a survey of chief academic officers, Allen et al. (2016, p. 21) found that $63 \%$ of these leaders believe that online education is critical to their institutions' longterm strategy.

The views of administrators may be shaped by the financial success of online programs at some early entrants into the online market. ${ }^{1}$ These institutions generated positive net revenue from their online programs and used it to cross-subsidize other programs and activities (Ortagus \& Derreth, 2020). The positive net revenues associated with online programs relate to the presence of economies of scale and scope (Cheslock et al., 2016). The economies of scope limit the expenditure increase caused by the addition of an online program, while the economies of scale cause these new expenditures to be outpaced by new revenues once enrollments reach a certain threshold.

The experiences of some schools have limited applicability to all schools due to the “collective rationality" problem (Hannan \& Freeman, 1977, p. 932). The number of students wanting an online education is not infinite, so the number of schools that can achieve a substantially-sized online program is limited. The number will be much smaller if online education is primarily concentrated, with a small number of higher education institutions enrolling most students, rather than fragmented, with large numbers of institutions enrolling meaningful numbers of online students. Researchers have not examined this topic despite the growing importance of online enrollment patterns. The number of students taking all of their coursework online increased by around 22\% between Fall 2012 and Fall 2018, while the number of students taking in-person classes fell by around $9 \%$. If online enrollments continue to grow as expected, they will increasingly shape the U.S. higher education system. To shed light into this increasingly important topic, this paper examines concentration levels in online education and how these levels change over time when the size of the online market expands.

We start by applying the lessons from Sutton's endogenous fixed cost model to online education (Shaked \& Sutton, 1987; Sutton, 1991, 1998). Although higher education

\footnotetext{
${ }^{1}$ See Blumenstyk (2018), Carlson (2014), Stripling (2015), and Straumshein (2017) for descriptions of the financial success of online programs at Brenau University, Liberty University, Simmons College, and Southern New Hampshire University.
} 
researchers have highlighted the fixed costs that an institution must absorb in order to enter the online market with educational offerings that meet a basic level of quality (Jones, 2004; Meyer, 2006; Rumble, 1997), they have not similarly emphasized the role of fixed costs that are endogenous in that they rise with the level of quality. As our upcoming review of theory will attest, the presence of endogenous fixed costs can have significant implications for concentration levels in the market for online education if enrollments continue to expand as expected. Although basic scale economies become a weaker barrier to entry as market size grows, endogenous fixed costs, which increase with market size, can continue to prevent higher education institutions from creating successful new online programs even after market size becomes large. We apply these insights from Sutton's model to predict online enrollment patterns.

We then employ the available data on online enrollments contained within the Integrated Postsecondary Education Data System (IPEDS), which spans the Fall 2012 to Fall 2018 period, to provide the first detailed description of market concentration in online education. Our work has four important features. First, we account for different dynamics at the local and national level by separately estimating k-organization concentration ratios for nonresident students and for 50 state-specific sets of resident students. Second, we explore how concentration ratios change as the definition of exclusively online enrollment narrows. Third, we compare enrollment patterns for online education to patterns for in-person education to provide a point of reference for online enrollments. Fourth, we examine how the role of the for-profit sector differs between in-person and online education, which indicates how opportunities for profit generation might vary between these two types of education.

We conclude the paper with a discussion that shifts attention away from higher education institutions and towards students. As institutions seek to sustain themselves financially, students are affected by their actions. We outline how concentration patterns could relate to institutional expenditure and tuition price patterns, and describe opportunities for further research into these areas. We also discuss how the ideas and findings in this paper relate to policy debates and research opportunities regarding practices such as expensive marketing campaigns (Cellini \& Chaudhary, 2020) and the use of online program managers (Carey, 2019; Hall \& Dudley, 2019).

\section{Related Literature}

The existing literature on enrollment patterns across institutions within the U.S. higher education system focuses primarily on in-person education. Past work described two broad historical transformations for in-person education. The first change relates to expansion in both the number of higher education institutions and the enrollment size of institutions as the demand for higher education grew over decades and centuries (Geiger, 2015; Goldin \& Katz, 1999; Kwoka \& Snyder, 2004). The second change relates to the distribution of students across institutions as the higher education industry moved from a collection of geographically isolated autarkies to a national market in which geographically disparate universities compete for the same students (Hoxby, 1997, 2009). Although the majority of students continued to attend nearby institutions after this shift, students with the strongest academic credentials increasingly enrolled in the most prestigious colleges, which led to greater between-institution inequality and smaller within-institution inequality in student test scores (Hoxby, 1997, 2009). These enrollment shifts did not lead to extremely large enrollment at any one institution, because national institutions restricted enrollment due 
to their focus on selectivity while local institutions were constrained by the size of nearby populations (Winston, 1999).

Researchers have not similarly examined enrollment patterns for online education, but they have investigated topics that shape enrollment patterns. ${ }^{2}$ Ortagus and Yang (2018) found a negative relationship between changes in state appropriation funding and changes in online enrollment at public 4-year institutions, suggesting that financial challenges may spur institutions to launch and grow online programs. Skinner (2019) found that online enrollments were smaller at open admission public institutions when nearby broadband speeds were at the lower end of the spectrum.

While studying the economics of online education production, higher education researchers have noted that organizational scale could play an important role within online education (Jones, 2004; Meyer, 2006; Rumble, 1997). These authors described potential economies of scale in online education driven by substantial initial set-up costs and low marginal costs associated with expanded enrollments. Because schools would be hesitant to absorb set-up costs when the number of online students is not large, these costs can serve as a barrier to entering the online market and lead to a small number of schools capturing the available pool of online students. Empirical research documenting economies of scale in online education is sparse due to data limitations, ${ }^{3}$ but authors have carefully specified the activities associated with the development, delivery, and administration of online education and described how each activity is likely to impact costs (Jones, 2004; Meyer, 2006; Rumble, 1997).

Industrial organization economists have long examined general questions pertaining to concentration. Ellickson (2015) provided a helpful overview of the approaches utilized in this literature, including the bounds approach associated with Sutton's endogenous fixed cost model. Researchers have applied Sutton's model to a range of industries, including book retailers (Latcovich \& Smith, 2001), supermarkets (Ellickson, 2007), restaurants, and newspapers (Berry \& Waldfogel, 2010). Although the model has not been applied to the case of higher education at length, Cowen and Tabarrok (2014) noted that Sutton's model has great relevance to online education.

\footnotetext{
${ }^{2}$ Our focus in this paper lies with how online enrollment patterns vary across institutions. A substantial literature examines how online enrollment patterns vary across students. Xu and Xu (2020) provide an excellent overview of this literature, and we direct interested readers to that review rather than provide an abbreviated version here. The authors also review research regarding other important topics pertaining to online education, most notably the impact of online education on student outcomes.

${ }^{3}$ Brinkman and Leslie (1986), Cheslock et al. (2016), Toutkoushian and Lee (2018), and Zhang and Worthington (2018) reviewed past research pertaining to economies of scale and scope in higher education. Previous research in this area did not differentiate between online and in-person education due to data limitations. In practice, the studies primarily identify patterns for in-person students, because most variation across institutions, especially during earlier years, are driven by differences in in-person enrollments and expenditures. In general, past research found that economies of scale are present, especially at lower levels of enrollment. Researchers also found evidence suggesting that economies of scope are present, especially for graduate education and research.
} 


\section{Sutton's Endogenous Fixed Cost Model}

\section{Introduction to the Model}

Berry and Waldfogel (2010) provided a concise and effective overview of Sutton's model, and we utilize the structure and equations from their overview here. They employed three equations to capture key considerations relating to consumers (e.g., students) and organizations (e.g., universities). The first equation contains a utility function for a consumer $\mathrm{i}$ considering a product $\mathrm{j}$ :

$$
\mathrm{U}_{\mathrm{ij}}=\theta_{\mathrm{i}} \delta_{\mathrm{j}}-\mathrm{p}_{\mathrm{j}}-\gamma\left(\mathrm{v}_{\mathrm{i}}-\mathrm{x}_{\mathrm{j}}\right)^{2}
$$

In this model, $\delta_{j}$ represents vertical dimensions of quality. If $\delta_{j}$ were to increase, all consumers would value product $\mathrm{j}$ more highly. For example, all consumers prefer faster processing speeds for computers and smart phones. In contrast, the term $\mathrm{x}_{\mathrm{j}}$ represents horizontal dimensions of quality, whose valuation differs across consumers. For example, consumers differ in the preference for sweetness in iced tea. The valuation of product $\mathrm{j}$ would depend upon the distance between desired product attributes of the individual consumer $\left(\mathrm{v}_{\mathrm{i}}\right)$ and the actual attributes of the product $\left(\mathrm{x}_{\mathrm{j}}\right)$. The remaining parameters play the following roles: $\gamma$ represents the importance of horizontal dimensions of quality in shaping the utility of consumers, $\theta_{\mathrm{i}}$ represents the importance of vertical dimensions of quality, and $\mathrm{p}_{\mathrm{j}}$ is the price of product $\mathrm{j}$.

The key organizational considerations relate to the cost structure of producing the product, and the below equations describe the factors shaping variable and fixed costs of the organization.

$$
\begin{gathered}
\operatorname{VC}\left(\mathrm{q}_{\mathrm{j}}, \delta_{\mathrm{j}}\right)=\mathrm{q}_{\mathrm{j}} \mathrm{mc}\left(\delta_{\mathrm{j}}\right) \\
\mathrm{FC}=\mathrm{FC}\left(\delta_{\mathrm{j}}\right)
\end{gathered}
$$

$\operatorname{VC}\left(\mathrm{q}_{\mathrm{j}}, \mathrm{\delta}_{\mathrm{j}}\right)$ represents the variable costs of producing product $\mathrm{j}$ at a quantity level of $\mathrm{q}_{\mathrm{j}}$ and a (vertical) quality level of $\delta_{\mathrm{j}}$. For simplicity, the equation for variable costs assumes that marginal cost, mc, is constant in quantity $\left(\mathrm{q}_{\mathrm{j}}\right)$ and is increasing in quality $\left(\delta_{\mathrm{j}}\right) \operatorname{FC}\left(\delta_{\mathrm{j}}\right)$ represents the fixed costs, which depends on $\delta_{j}$ but by definition does not depend on $q_{j}$.

The model has three implications that are important for the purposes of this paper. First, when increases in quality $\left(\delta_{\mathrm{j}}\right)$ lead to large increases in variable costs, $\operatorname{VC}\left(\mathrm{q}_{\mathrm{j}}, \delta_{\mathrm{j}}\right)$, but not fixed costs, $\operatorname{FC}\left(\delta_{\mathrm{j}}\right)$, concentration levels will likely fall when market size expands. ${ }^{4}$ The rationale for this claim is that organizations offering high-quality products must charge substantially higher prices than organizations offering low-quality products in order to cover the high marginal costs associated with quality. As market size increases, organizations will have a greater incentive to enter the market with a product containing specific combinations of price and quality that match the tastes of specific bands of customers. In turn, this entrance reduces concentration.

\footnotetext{
4 The shape of the relationship between quality enhancements and costs is also an important consideration (Berry \& Waldfogel 2010). If marginal cost is increasing and convex in quality, then we should expect market size increases to lead to fragmentation. But if marginal cost is increasing and concave in quality, then concentration may persist as the size of the market increases.
} 
Second, a market may remain concentrated as it grows if increases in $\delta_{j}$ lead to large increases in fixed costs, $\mathrm{FC}\left(\delta_{\mathrm{j}}\right)$, but not variable costs, $\mathrm{VC}\left(\mathrm{q}_{\mathrm{j}}, \delta_{\mathrm{j}}\right)$. In this case, fixed costs associated with items such as advertising and R\&D play a significant role in shaping quality (i.e., customers' valuation of the product). These costs are endogenous as they relate to a choice variable for the organization pertaining to quality rather than basic set-up costs. As markets expand, the equilibrium level of endogenous fixed costs grows, so the barrier to entry associated with these fixed costs may not diminish in importance as it does with scale economies. Furthermore, organizations offering low-quality products will have difficulty competing, because high-quality products can be priced at similar levels as low-quality products when markets are large and fixed costs can be spread across a large number of consumers. For these reasons, the presence of endogenous fixed costs can cause a market to remain concentrated as its size expands.

Third, although Sutton's results hold when horizontal dimensions of quality are present, the market will be relatively less concentrated when these dimensions are important, because more organizations will enter the market and specialize to meet the tastes of specific bands of consumers (Sutton, 1991). A key horizontal dimension of quality relates to the distance between consumers and organizations. When consumers prefer nearby organizations, more organizations will enter the market to serve nearby populations.

Before we apply this model to higher education, we need to address one potential source of confusion regarding the term quality. This term is used very differently within the industrial organization literature in economics than within higher education journals. Within economics, the term essentially relates to the valuation of enrollment opportunities by prospective students. A student is more likely to enroll in an online program if she assigns a high valuation to the program and is less likely to enroll if she assigns a low valuation. Colleges and universities can shape a student's valuation by increasing its advertising or increasing its investment in activities such as instruction and student services. In regard to concentration levels, the degree to which different types of expenditures shape valuation is irrelevant within Sutton's model. The key issue is that an institution will have difficulty attracting students if it does not spend sufficient funds on the types of expenditures that shape valuation. As we will discuss later in this paper, the impact of spending on student learning and societal well-being will vary across alternative types of expenditures.

\section{Application of the Model to Higher Education}

Sutton's model, and industrial organization theory in general, assumes that the sole objective of organizations is to maximize profits. This assumption aligns with the behavior of for-profit colleges and universities, which seek to distribute profits to their owners. In contrast, nonprofit institutions, especially publicly-controlled ones, are motivated by a more complex set of objectives that includes non-financial objectives such as the provision of access to district or state residents. Due to these differences by sector, we should expect Sutton's model to better predict enrollment patterns in the for-profit sector than in the nonprofit sector. Similar to the organizations in the model, we expect for-profit institutions to not enter the online market in the presence of fixed costs unless they can attain scale so that these costs are spread across a large number of students. Contrastingly, in order to meet non-financial objectives, nonprofit institutions may sometimes choose to enter the online market even if they cannot obtain the scale required for positive net revenue. When scale can be achieved, nonprofits may be less driven to obtain the exact level of scale that would maximize net revenue because financial objectives are less central to these organizations. 
If fewer for-profit institutions enter the online market and those that do disproportionately operate at scale, then online enrollments will be more concentrated in the for-profit sector than in the nonprofit sector.

Although financial considerations are less central to nonprofit institutions, they still shape decision-making pertaining to online education. Slaughter and Leslie (1997) and Slaughter and Rhoades (2004) describe how nonprofit colleges and universities increasingly engage in academic capitalism by emphasizing financial considerations within their decision-making. This practice may be especially prevalent in online education, because Sjogren and Fay (2002) note that administrators often expect online courses and programs to more than pay for themselves.

When nonprofits, especially public institutions, do consider non-financial objectives pertaining to online education, they are most likely to do so for online programs targeted at state residents (rather than online programs oriented towards the national market). A public institution may create a locally-oriented online program in an area of need for the state even if the program does not generate positive net revenue. In contrast, a for-profit institution will be very unlikely to create an online program for non-financial reasons.

These distinctions by organizational sector and student residency can sharpen predictions regarding a central question: How will concentration levels in online education change as the size of the online market expands? If we relied upon Sutton's model to answer this question, the salient concern would then become whether or not a student's valuation of an online program (i.e., quality) is primarily determined by factors relating to the institution's spending on fixed costs. Journalistic accounts of large online providers suggest that these schools spend considerable amounts of money on fixed costs relating to recruitment, student services, and course development, which can all shape potential students' valuation of their educational offerings (Blumenstyk, 2018; McKenzie, 2019). These investments fund items like national marketing campaigns and improvements to studentinformation systems. If the activities associated with fixed costs are central for attracting and retaining students, then institutions that do not spend heavily on them will have difficulty building their enrollments. Sutton's model implies that the needed level of spending will grow as the size of the online market expands. Only a small set of schools will find it in their financial interest to spend at these levels, and as a result, this small set of schools will be able to capture a substantial share of enrollments.

Because Sutton's model better aligns with decisions pertaining to nationally-oriented programs than locally-oriented programs, we should expect nonresident enrollment patterns and resident enrollment patterns to react differently to increases in the online market. For nonresident enrollment, we would adopt the prediction emanating from the model: Nonresident online enrollment will be concentrated and remain concentrated even after the online market expands. ${ }^{5}$ Relatively few institutions will expend the resources that are required for successful competition in regional or national online markets.

We might expect a different pattern for resident enrollments for two reasons. First, nonfinancial objectives not present in Sutton's model (i.e., a commitment to providing access to state residents) will encourage public institutions to respond to growing student interest by launching online programs for resident students. ${ }^{6}$ Second, financial considerations may

\footnotetext{
5 Sutton's model does not imply that concentration will not fall at all with market size, but it does imply that a lower bound for concentration will be present and the online market will stay relatively condensed.

${ }^{6}$ An alternative consideration is that the state also shares a commitment to expanding access for local students and provides the institution with a subsidy for operating online programs that causes the institution to
} 
not deter market entry, because locally-oriented programs may not require large spending on marketing or other areas if some prospective online students prefer nearby institutions (i.e., if horizontal dimensions of quality are important). Although online students value proximity less than in-person students do, they likely still possess at least a weak preference for local institutions. ${ }^{7}$ If an expanding market allows an institution to attract a meaningful number of nearby students due to a preference for local schools, the institution's entrance into the online market may not produce substantial financial losses and might even produce gains. ${ }^{8}$ For the two reasons noted in this paragraph, we would expect concentration levels for resident online enrollment within a specific state to be more likely to fall as the size of the online market expands.

Although our focus is on online education, our empirical analysis will also include an examination of in-person enrollment patterns in order to provide a point of reference. Industrial organization theory provides three considerations that suggest online enrollments will be more concentrated than in-person enrollments. First, as noted earlier, horizontal dimensions of quality relating to geographical proximity are less important in online education, because online students do not need to relocate in order to enroll at non-local institutions. Second, economies of scale are stronger in online education than in-person education due to the lower marginal costs associated with enrollment increases (Cowen \& Tabarrok, 2014; Jones, 2004; Meyer, 2006). ${ }^{9}$ Third, the size of the market for online education is currently small relative to the size of the market for in-person education.

Footnote 6 (continued)

generative positive net revenue from the online programs even though their costs exceed the generated net tuition revenue.

7 Proximity is less important for online education than in-person education, because online students do not need to move away from family members, find new employment, or make other adjustments in order to enroll at non-local institutions. Online students may still possess at least some preference for local institutions for a variety of reasons. They may have limited information about non-local choices, an affinity for local institutions for sentimental reasons, a desire to network with local students, and a belief that local employers will prefer local degrees. In addition, some online students may want the option of taking a portion of their coursework in an in-person setting or the option of obtaining help through visits to physical offices. A portion of online students may have initially intended to enroll in-person at a local institution and only moved into online coursework at that institution after finding that the timing of in-person courses did not align with their schedules. A final consideration relates to price, as the in-state or in-district tuition prices at public institutions may be lower than the relevant prices of other institutions.

8 The financial impact will be most positive for online programs in fields associated with strong student demand and areas of strength for the institution, especially if the programs can be offered with a targeted curriculum and other features that lower costs.

9 The marginal costs of space are clearly lower for online education, most notably in the area of classrooms. The marginal costs of instructional personnel will also be lower when online courses are delivered partially or fully asynchronously. The creation of digital materials for asynchronous courses leads to high fixed costs, but the presence of digital materials can allow the delivery of individual sections of the course to use less faculty time, lower cost labor, or both (Meyer, 2006). The lower costs of labor in the delivery of an online course is consistent with theoretical work highlighting the narrower range of activities covered by online instructors (Acemoglu, Laibson, \& List, 2014) and empirical work that finds that instructor effects are smaller in online settings than in traditional classrooms (Bettinger et al. 2015; De Vlieger, Jacob, \& Stange 2016). 


\section{Data and Methods}

Our primary data source is IPEDS. We extracted institution-level data from the IPEDS Fall Enrollment survey component-specifically the Fall Enrollment by Distance Education Status sub-component and the Residence and Migration sub-component-and the IPEDS Institutional Characteristics survey component. ${ }^{10}$ The analysis period is Fall 2012 through Fall 2018, which represent all years for which distance education enrollment data are available.

The analysis sample is the universe of Title IV institutions. A Title IV institution is an organization that provides postsecondary education and is eligible to enroll students who receive Title IV federal financial aid (Congressional Research Service, 2007). ${ }^{11}$ Title IV institutions must obtain institution-level accreditation by an accrediting agency recognized by the U.S. Department of Education and satisfy requirements stipulated in the Program Participation Agreement (PPA) contract with the U.S. Department of Education, including annual completion of all components of the IPEDS survey. A Title IV institution may be a single-campus institution or a multi-campus institution with a main campus and one or more branch campuses. ${ }^{12}$ Because multiple campuses from the same Title IV institution sometimes report enrollment data separately, we aggregate data reported at the campuslevel to the Title IV institution-level using digits 2-5 of the Office of Postsecondary Education Identification (OPEID) code as recommended by Jaquette and Parra (2016).

The IPEDS Fall Enrollment component represents an annual fall snapshot of the number of students enrolled in courses for credit, including both degree-seeking students and nondegree-seeking students. The Fall Enrollment by Distance Education Status sub-component identifies three types of students with respect to mode of education (U.S. Department of Education, 2017): First, "enrolled exclusively in distance education courses," defined as students who are enrolled only in courses that are considered distance education courses; second, "enrolled in some but not all distance education courses," defined as students who are enrolled in at least one course that is considered a distance education course, but are not enrolled exclusively in distance education courses; and, third, students "not enrolled in any distance education courses." ${ }^{13}$ For the analysis reported in this paper, we combine the latter two categories because students who enroll in some in-person coursework will face similar

\footnotetext{
${ }^{10}$ Rather than examine data on enrollments, we could alternatively examine data on net tuition revenue to measure concentration levels for in-person and online education. The available financial data for higher education institutions do not allow for such analysis, however, because revenues for in-person and online education are combined rather than reported separately. Consequently, we solely use enrollment data when describing concentration levels separately for in-person and online education.

11 Our focus on Title IV institutions means that enrollments at some providers of online education will not be included. Cellini and Goldin (2014) highlight the substantial number of for-profit institutions that do not participate in Title IV programs. Non-traditional providers, such as Massive Open Online Course (MOOC) providers and coding boot camps, are also excluded from our analysis.

12 An additional complexity is that the same organization may own several Title IV institutions. For example, Empire Beauty School-a national, for-profit organization that awards cosmetology degrees-owns several separately accredited Title IV institutions. The practice of owning multiple Title IV institutions is almost solely restricted to the for-profit sector. Arguments exist for and against further aggregating the data to the firm-level, but further aggregation is impossible for practical reasons. No identification variable accurately tracks ownership.

13 See Poulin and Hill (2014) and Straut and Poulin (2016) for helpful discussions about the challenges that individual colleges and universities face when seeking to follow the reporting instructions provided by the U.S. Department of Education. These challenges led to the overcounting of distance education students in some contexts and undercounting in other contexts. The net effect of these errors is unknown.
} 
geographical constraints during the college choice search as students who enroll entirely in in-person coursework. For brevity, we refer to enrollment for this combined group as "inperson enrollment." Our results do not differ qualitatively when we instead solely use the last category to measure in-person enrollment.

To examine how the market structures for online and in-person education relate to geography, we separately examine resident and nonresident enrollments. We obtained resident and nonresident online enrollments from the Distance Education Status sub-component, which collects enrollment data separately for online students who are located in the same state as their institution and for online students who are located in a different state or country as their institution. To create measures of resident and nonresident enrollment for inperson students, we used the Residence and Migration sub-component. This sub-component contains limitations as it only collects data for first-time undergraduate students and does not report figures separately for online and in-person students. We are able to make adjustments to account for some of these limitations, because the Distance Education Status sub-component also includes figures reported separately for undergraduate and graduate students. ${ }^{14}$

We also examine how concentration levels change when we adjust our definition of online students. IPEDS reports enrollment patterns based solely upon the fall semester in question rather than the student's degree program. A student who reports enrolling exclusively in online courses during the Fall 2018 semester, for example, may take in-person courses during other semesters. Students who take both in-person and online coursework in their degree program should have less concentrated enrollment patterns than students who take their entire degree program online, because the former students are more likely to attend higher education institutions that are geographically proximate. IPEDS data will consequently provide a limited portrait of the enrollment choices of students desiring an exclusively online education and the enrollment outcomes of institutions that offer exclusively online degree programs.

The 2012 National Postsecondary Student Aid Study (NPSAS) contains information that, when used in conjunction with IPEDS, can produce rough enrollment estimates for the number of students whose entire degree program is online. Unlike other editions of NPSAS, NPSAS:12 asked students both whether all of their coursework for the academic year was entirely online and whether their entire degree program was entirely online. We used this information to calculate estimates of "online degree program" enrollments for each school via three steps. First, we estimated logit regressions where the probability that

\footnotetext{
${ }^{14}$ We make two types of adjustments. The first is simple: We only examine undergraduate students when making comparisons between in-person and online enrollment that relate to geography. This adjustment has little effect on the findings reported in this paper, because the relevant results for online enrollments do not meaningfully vary by level (undergraduate vs. all). The second type of adjustment is related to calculations of resident and nonresident enrollments for in-person students. Because the Residence and Migration subcomponent does not distinguish between online and in-person students, the available enrollment figures represent all students rather than just in-person students. To produce estimates specific to in-person students, we developed a correction procedure that removes online students from these enrollment figures using estimates of the online share of students and the resident share of online students from the Distance Education Status sub-component. The results for in-person students based on this procedure (that are reported later in Table 4) are very similar to results based on uncorrected figures, which is unsurprising because online students still represent a small portion of the student body at most institutions. The available data do not allow us to make adjustments for one last limitation present in IPEDS data, that the Residence and Migration sub-component reports enrollment levels for first-time freshmen while the Distance Education Status subcomponent reports enrollment levels for all students.
} 
an "online" student is in an "online degree program" depends upon several key variables that relate to market concentration. ${ }^{15}$ Second, we multiplied the coefficients from this logit regression by the relevant values for each institution in our sample to produce adjustment parameters for each school. Third, we multiplied these adjustment parameters by the original IPEDS measures of "online" enrollment to produce estimates of "online degree program" enrollment. ${ }^{16}$ As we will discuss in more detail in the results section, our findings do not generally change when we use these adjusted enrollments rather than the originally reported IPEDS enrollments. The primary difference is that our estimates of online enrollment concentration increase in magnitude when adjusted enrollments are used.

To assess concentration levels, we report k-organization concentration ratios, which measure the combined share of total enrollment of the largest $\mathrm{k}$ universities. Although we examined a wide range of concertation ratios and other measures (e.g., Herfindahl index), we report concentration ratios for 1,2, 5, 10, and 20 institutions because we found that these five concentration ratios describe the observed concentration patterns well. We also report basic descriptive statistics and the number of institutions within certain enrollment bands in order to more fully describe the distribution of enrollments across higher education institutions. Because enrollment patterns differ meaningfully across sectors, we report results separately for public, private nonprofit, and private for-profit institutions after reporting results for all institutions.

\section{Results}

\section{Market Concentration in Online Education}

While applying Sutton's model to the U.S. higher education system, we predicted that online nonresident enrollment would be concentrated and would remain concentrated as the size of the online market grows over time. We also predicted that resident enrollment concentration would be more likely to fall as market size expands for reasons both related and unrelated to the model. Table 1 reports concentration ratios estimated separately for nonresident (panel B) and resident (panel C) students. Consistent with our expectations, the concentration ratios computed solely using data for nonresident students reveal highly concentrated enrollments. In 2018, the two institutions with largest online nonresident enrollments accounted for a bit less than 1 out of every 6 online nonresident students $(15.5 \%)$. The largest five institutions enrolled a bit less than 1 out of every 3 students (30.5\%). The share moved close to one-half (45.1\%) for the 10 largest institutions and well over one-half $(59.6 \%)$ for the 20 largest institutions.

\footnotetext{
15 The independent variables used in the logit regression were an indicator for resident student status, the percentage of students enrolled exclusively online at the institution attended, and indicators for the control and degree level of the institution attended. Because IPEDS online enrollment is determined by the fall semester and NPSAS is determined by the academic year, NPSAS-based estimates of the probability that an "online" student is in an "online degree program" will be a slight over-estimate of the relevant probability for IPEDS.

16 Separate adjustment parameters were calculated for resident and nonresident students at each school. Each adjustment parameter was then multiplied by the relevant measure of "exclusively online" enrollment (resident or nonresident), and the resulting two products were summed to produce our estimate of "exclusively online degree program" enrollment.
} 


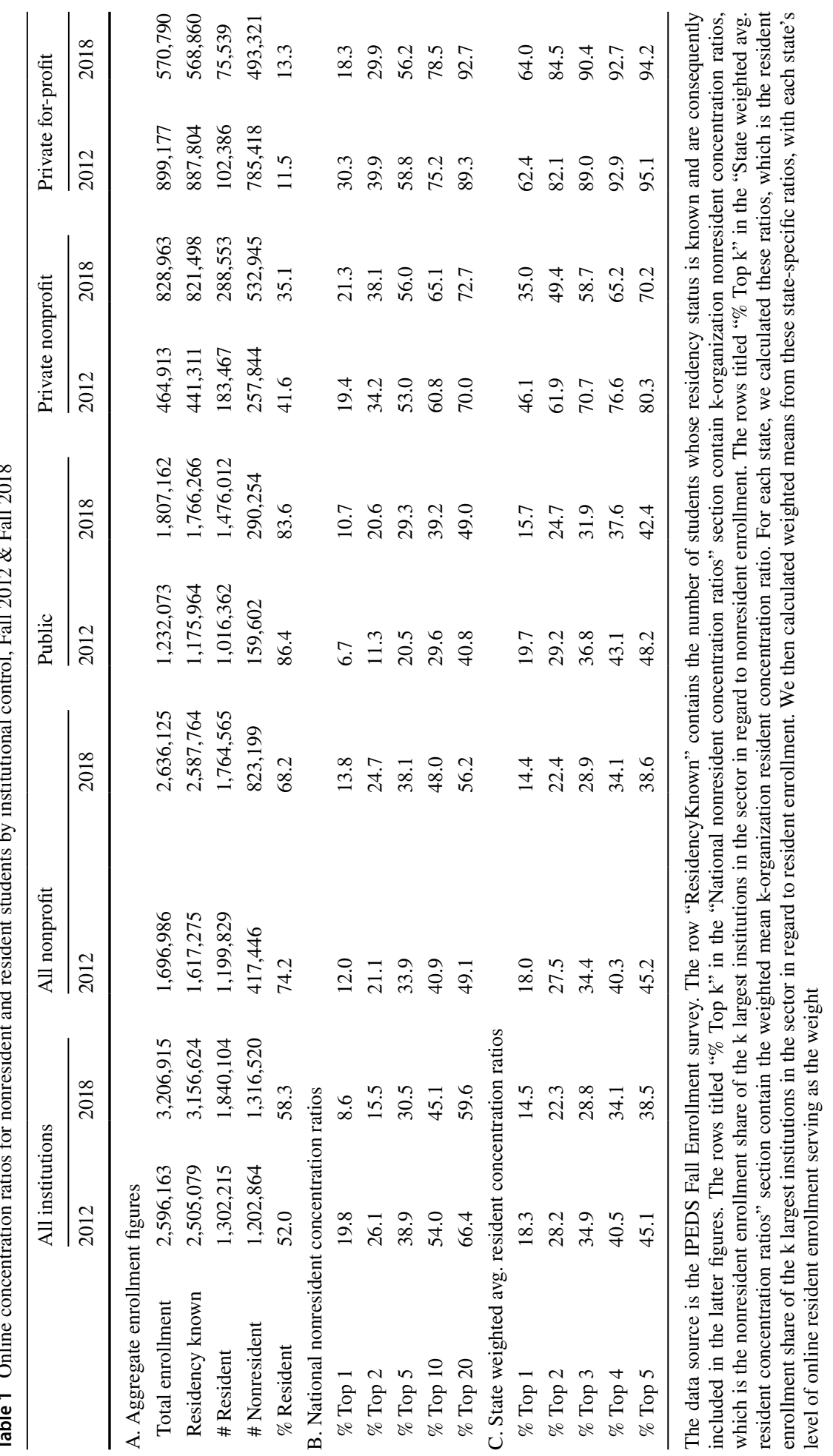


The overall changes in concentration levels did not align with our expectations when all institutions were examined but did align when only nonprofit institutions were examined. Concentration ratios fell between 2012 and 2018 in the former case and rose in the latter case. These varying results relate to a dramatic drop in online enrollments within the for-profit sector, which initially contained the largest providers of online education. After rapid enrollment growth during the 2000s, large for-profit institutions struggled to attract online students in the 2010s amid poor outcomes for online students at for-profits, new federal regulations, and intensive media coverage of troubling organizational behavior (Cellini \& Turner, 2019; Fabina, 2019; Fountain, 2019; Kinser \& Zipf, 2019). Nonresident online enrollment declined by almost 300,000 students for the for-profit sector. In contrast, nonresident online enrollment increased by slightly over 400,000 students at nonprofit institutions. These new enrollments at nonprofits were heavily captured by the largest providers, which caused nonprofit concentration ratios to increase.

As the for-profit share of nonresident enrollments steadily fell from 65 to $37 \%$ between 2012 and 2018, the enrollment reductions in the for-profit sector had a declining influence on overall concentration levels. Figure 1 reports nonresident concentration ratios for each year, with separate results by institutional type. Overall concentration levels plateaued near the end of the period and even slightly increased between 2017 and 2018. The trends for the nonprofit sector increasingly shape overall trends, and concentration ratios are not falling for this sector. If these trends persist, a relatively small number of higher education institutions will continue to enroll most nonresident online students. Although overall nonresident concentration levels have fallen since 2012, a meaningful amount of concentration remains. For both the nonprofit and overall market in Fall 2018, the majority of nonresident online enrollments are captured by fewer than 15 higher education institutions.

Panel $\mathrm{C}$ of Table 1 reports figures that describe concentration levels for resident students. For each individual state, concentration ratios were computed using resident enrollment solely for that state (e.g., Michigan residents enrolled online at Michigan postsecondary institutions). Weighted means were then computed from these 50 state-specific ratios, with each state's level of online resident enrollment serving as the weight.

As expected, the results reveal very different patterns for nonresident students. Statespecific resident concentration ratios were similar to national nonresident concentration ratios, especially for the nonprofit sector, even though individual states only contain a small fraction of the total number of higher education institutions. The five largest online institutions in a state typically captured around one-third of all online resident enrollments while the five largest online institutions in the nation acquired a similar share of all online nonresident enrollments.

The results reveal that resident student concentration levels fell during our period, on average. ${ }^{17}$ The trends are very similar for the overall market and for the nonprofit sector, because for-profit institutions primarily enroll nonresident students. The reductions in concentration are meaningfully sized, as concentration ratios generally dropped by 4-6 percentage points. These declines occurred steadily throughout the period as each concentration ratio fell for each year-to-year change.

In summary, Table 1 highlights three different trends in the market for online education: falling nonresident concentration due to declines in enrollment at large for-profit institutions, slightly increasing nonresident concentration within the nonprofit sector, and falling

\footnotetext{
17 Not all states experienced a reduction in concentration over the period. For most concentration ratios, around 9-13 states experienced an increase in concentration.
} 
resident concentration within most states. The trend for the entire online market will reflect these three trends as well as trends in the share of students who are resident students. ${ }^{18}$ Although we do not report the findings here, we also examined concentration ratios for total online enrollment for each year during the 2012-2018 period. The trends for these concentration ratios are very similar to those reported for nonresident students in Table 1 and Fig. 1. Ratios fell for all institutions but rose slightly for nonprofit institutions. The negative trend for all institutions plateaued near the end of the period and slightly increased between 2017 and 2018 .

Table 2 reports concentration ratios for total online enrollment in 2018. Because the national distribution of resident enrollments is relatively fragmented, these concentration ratios for total enrollments are lower than their nonresident-specific and resident-specific counterparts from Table 1. That said, a meaningful amount of concentration remains. For example, the largest 10 institutions in regards to online enrollment capture $20.8 \%$ of the online market. The sector-specific ratios reveal much lower concentration in the public sector than in the private nonprofit and for-profit sectors, which is a byproduct of relatively large online resident enrollments in the public sector and relatively large online nonresident enrollments in the other two sectors.

Table 2 also reports concentration ratios for our estimates of enrollments in exclusively online degree programs. Our IPEDS measure of online enrollments includes students who are enrolled online for the fall semester in question but not for all of their coursework in their degree program. Data from NPSAS: 12 indicate that around 83\% of students who are enrolled exclusively online during the 2011-2012 academic year were enrolled in a degree program that was entirely online. The results from a logit regression, reported in Appendix Table 6, reveal that this share varies across several key variables that relate to market concentration. $^{19}$

Using the procedures outlined in our data and methods section, we used these regression results to produce institution-level estimates of enrollments in exclusively online degree programs. We then used these enrollment estimates to produce concentration ratios for this narrower definition of online enrollment, which are reported in Table 2. The results indicate that concentration ratios are 20-25\% higher than the ratios produced by unadjusted IPEDS online enrollments. ${ }^{20}$ The ratios are higher for the narrower definition, because

\footnotetext{
18 The share of students who are resident students will be influenced by factors relating to our earlier theoretical discussion. As market size grows, two factors will affect the residency choice of students. First, the vertical quality of national providers will grow as they increase their spending on endogenous fixed costs. Second, local providers will increasingly enter the market at the organization-level and program-level. The first factor will push the share of students who are resident students downward while the second factor will push it upward.

19 Students enrolled exclusively online during the 2011-12 academic year were more likely to be in an entirely online degree program when they were nonresident students and when they were enrolled at higher education institutions where online enrollment comprised a larger share of overall enrollments. The likelihood also varied by Carnegie classification and degree-level, with the highest rates at four-year for-profit institutions followed by less-than-four-year for-profit colleges, four-year private nonprofit institutions, fouryear public institutions, and finally, less-than-four-year public colleges.

20 These differences cannot be explained by the propagation of errors within the multi-step logistic regression process. For the concentration indices in Table 2 associated with estimated online degree program students, we computed $95 \%$ confidence intervals through bootstrapping methods and found that the lower bounds of these intervals were still far above the concentration indices for unadjusted IPEDS online enrollments in Table 2. For example, the 95\% confidence interval for the share of estimated online degree program enrollments captured by the ten largest institutions ranges between 25.0 and 26.1. These figures far exceed 20.8, which is the share of unadjusted IPEDS online enrollments captured by the ten largest institutions.
} 


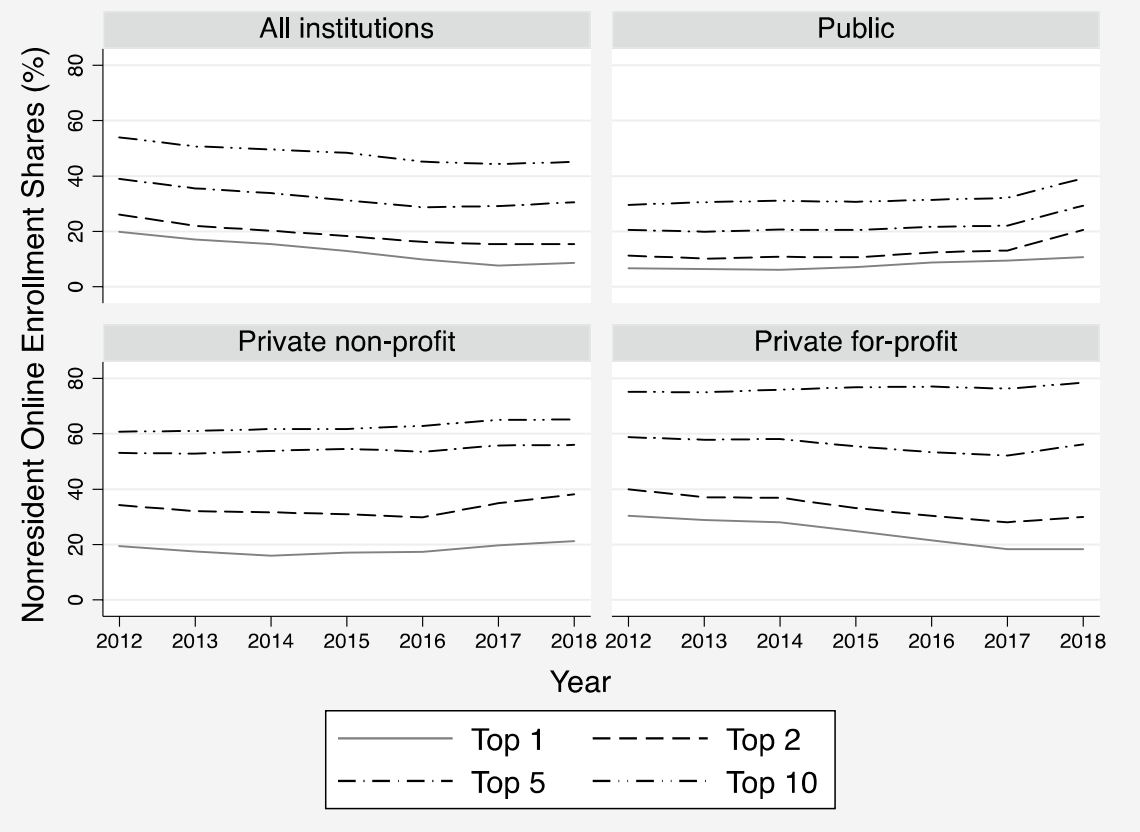

Fig. 1 Nonresident online enrollment concentration ratios

resident students at public institutions are most likely to enroll entirely in online classes for one term even though they are not in an exclusively online degree program. When a substantial portion of public resident enrollments is removed, the share of total online enrollments that are captured by large national providers becomes greater.

\section{Comparing Online Education with In-Person Education}

Table 3 contains 2018 figures for in-person education that are similar to those presented in Table 2 for online education. The results reveal that enrollment patterns for in-person education are much more fragmented. The 10 largest providers of in-person enrollment only capture $3.8 \%$ of total enrollment while the corresponding figure for online enrollments from Table 2 is $20.8 \%$. The differences are especially striking in the private sectors. In the private nonprofit sector, the largest 10 institutions capture around a tenth $(9.8 \%)$ of the inperson students, while the same ratio for online enrollments is almost one-half $(47.3 \%)$ of students. For the private for-profit sector, the corresponding figures are $16.6 \%$ and $75.0 \%$.

Concentration ratios are drastically higher for online education than for in-person education, because online education ratios have much smaller denominators (total enrollment) but have similarly-sized, and sometimes larger, numerators (enrollment of largest providers). Total enrollment for online education $(3,206,915)$ is one-fifth of total enrollment for in-person education $(16,653,084)$. Yet, the three largest providers of online education (Western Governors University, Southern New Hampshire 
Table 2 Adjusted and unadjusted online concentration ratios by institutional control, Fall 2018

\begin{tabular}{lccccccc}
\hline & \# Inst & Total enrollment & \% Top 1 & \% Top 2 & \% Top 5 & \% Top 10 & \% Top 20 \\
\hline Online students & & & & & & & \\
All institutions & 5162 & $3,206,915$ & 3.8 & 6.8 & 14.0 & 20.8 & 28.7 \\
All nonprofit & 3471 & $2,636,125$ & 4.6 & 8.3 & 14.0 & 18.7 & 23.3 \\
Public & 1828 & $1,807,162$ & 2.7 & 4.7 & 8.6 & 12.1 & 17.5 \\
Private nonprofit & 1643 & 828,963 & 14.6 & 26.3 & 40.2 & 47.3 & 56.1 \\
Private for-profit & 1691 & 570,790 & 16.9 & 29.2 & 52.6 & 75.0 & 89.8 \\
Estimated online degree-program students & & & & & \\
All institutions & 5162 & $2,557,992$ & 4.7 & 8.4 & 17.2 & 25.4 & 34.8 \\
All nonprofit & 3471 & $1,998,060$ & 6.0 & 10.7 & 17.7 & 23.5 & 28.6 \\
Public & 1828 & $1,235,433$ & 3.5 & 6.3 & 11.1 & 15.3 & 21.3 \\
Private nonprofit & 1643 & 762,627 & 15.6 & 28.1 & 42.6 & 49.9 & 58.8 \\
Private for-profit & 1691 & 559,932 & 17.0 & 29.3 & 52.9 & 75.4 & 90.1 \\
\hline
\end{tabular}

The columns titled "\% Top k" contain k-organization concentration ratios, which is the enrollment share of the $\mathrm{k}$ largest institutions in the sector. Online students are defined as students enrolled exclusively in distance education courses during the Fall 2018 semester. Online degree-program students are defined as students enrolled in an entirely online degree program. Online enrollments are taken directly from the IPEDS Fall Enrollment survey. Online degree-program enrollments are estimated using IPEDS and NPSAS data in the manner outlined in the text

University, and University of Phoenix) all had enrollments above 96,000, while the largest provider of in-person education (Pennsylvania State University) had an enrollment of 76,933.

Not only is the level of scale different for online than for in-person education, but the recipe for scale also differs. Large online providers achieve scale by primarily enrolling nonresident students while large in-person providers achieve scale by primarily enrolling resident students. Table 4 documents this point by reporting the average nonresident enrollment shares for specific enrollment bands for both online and in-person. Nonresident share and enrollment size are positively related for online education but not for in-person education.

The differences between in-person and online education described in this section align with the expectations stated earlier in this paper. Institutions can more easily scale their online programs than their in-person programs because expanding online enrollment slots at scale is less expensive (due to lower marginal costs) and filling online enrollment slots at scale is less challenging (due to the ease by which online students can attend distant institutions). The peculiar economics associated with inperson education also plays a role, because it leads top ranked institutions to respond to strong student demand by becoming more selective rather than scaling enrollments (Hoxby, 2009; Winston, 1999). Selectivity increases the academic credentials of incoming students and the subsidy level per student, two factors that determine student demand (Winston, 1999). The in-person students who are most willing to relocate for college typically enroll at well-resourced selective institutions (Hoxby, 2009). Thus, the institutions that seek to scale in-person education typically focus on local populations and are consequently constrained by the size of those populations. 
Table 3 In-Person concentration ratios by institutional control, Fall 2018

\begin{tabular}{lcclllll}
\hline & \# Inst & Total enrollment & $\%$ Top 1 & \% Top 2 & \% Top 5 & \% Top 10 & \% Top 20 \\
\hline In-person students & & & & & & & \\
All institutions & 5162 & $16,653,084$ & 0.5 & 0.9 & 2.1 & 3.8 & 6.7 \\
All nonprofit & 3471 & $16,050,426$ & 0.5 & 0.9 & 2.2 & 4.0 & 7.0 \\
Public & 1828 & $12,813,641$ & 0.6 & 1.2 & 2.7 & 5.0 & 8.7 \\
Private nonprofit & 1643 & $3,236,785$ & 1.6 & 2.8 & 5.8 & 9.8 & 15.7 \\
Private for-profit & 1691 & 602,658 & 3.3 & 5.3 & 10.1 & 16.6 & 26.2 \\
\hline
\end{tabular}

The data source is the IPEDS Fall Enrollment survey. The columns titled "\% Top k" contain k-organization concentration ratios, which is the enrollment share of the $\mathrm{k}$ largest institutions in the sector. In-person students are defined as students enrolled in at least one in-person course during the Fall 2018 semester

\section{Further Examination of the For-Profit Sector}

Comparing online and in-person enrollment patterns across sectors can reveal further insights. Tables 1 and 2 revealed that the for-profit sector was more concentrated than the nonprofit sector, and our earlier theoretical discussion predicted that would be the case because for-profit institutions are more likely to act in accordance with Sutton's model. Specifically, they will be less likely to enter the market and more likely to operate at scale when they do enter the market.

Table 5 reports a number of statistics that allow for examination by sector of both market entry and enrollment scale for institutions that enter. We do find that for-profit institutions are relatively unlikely to enter the online market, while public institutions, who are driven by access considerations alongside financial considerations, disproportionately choose to enter. The share of for-profit institutions with non-zero online enrollment is $9.2 \%$, while the corresponding share for public institutions is $80.9 \% .^{21}$ The difference narrows when we solely examine 4-year institutions, because less-than-4-year for-profit institutions are especially unlikely to enter the online market. $^{22}$

We also find that for-profit institutions are more likely to operate at scale. Among those institutions that entered the online market, $18.1 \%$ of 4-year for-profits enroll at least 5000 online students while the corresponding figures for 4-year public and private nonprofit institutions are $4.7 \%$ and $2.4 \%$. The mean enrollment at 4 -year for-profits is three times as

\footnotetext{
21 Private nonprofit institutions fall somewhere between the cases of public and private for-profit institutions. They are less likely to be driven by financial considerations than for-profit institutions and less likely to be driven by missions focused on providing access to local students than public institutions. Table 5 reveals that the share of four-year private nonprofit institutions that entered the online market was lower than the share of publics and higher than the share of for-profits. Further analysis reveals that four-year private nonprofit institutions were more likely than four-year public institutions to primarily (or entirely) enroll online students in graduate-level programs. This result suggests that many private nonprofit institutions that enter the online market at small enrollments may still be doing so for financial reasons, because an institution can produce positive net revenue when launching a graduate program in a specific field associated with strong student demand, an area of strength for the institution, or both. Graduate programs are financially attractive because an online professional master's degree, which typically has a targeted curriculum, can have relatively low fixed costs.

22 The low online market entry for less-than-four-year for-profit institutions is likely partially driven by the subject matter of many of these institutions. Cosmetology schools and some other trade-oriented schools may find that online instruction is an impractical way to provide the necessary "hands on" training.
} 
Table 4 Average nonresident undergraduate enrollment share by enrollment size, Fall 2018

\begin{tabular}{llllll}
\hline Enrollment size & \multicolumn{2}{l}{ Number of institutions } & & \multicolumn{2}{l}{ Avg. \% nonresident } \\
\cline { 2 - 3 } \cline { 5 - 6 } \cline { 5 - 6 } & Online & In-person & & Online & In-person \\
\hline All institutions & & & & \\
40,000 and above & 3 & 15 & & 93.5 & 13.7 \\
25,000-39,999 & 8 & 64 & & 76.3 & 18.8 \\
$10,000-24,999$ & 14 & 299 & & 55.2 & 14.9 \\
$5000-9999$ & 35 & 450 & & 38.8 & 16.3 \\
$2000-4999$ & 156 & 727 & & 13.3 & 22.5 \\
$1-1999$ & 2147 & 3321 & & 16.9 & 16.4 \\
$4-$ year institutions & & & & \\
40,000 and above & 3 & 10 & & 93.5 & 18.0 \\
$25,000-39,999$ & 8 & 53 & & 76.3 & 22.0 \\
$10,000-24,999$ & 9 & 192 & 67.9 & 21.3 \\
$5000-9999$ & 25 & 253 & 51.6 & 26.2 \\
$2000-4999$ & 78 & 429 & 22.9 & 34.2 \\
$1-1999$ & 1329 & 1135 & 22.8 & 34.5 \\
\hline
\end{tabular}

The data sources are the IPEDS Fall Enrollment survey and the IPEDS Resident and Migration survey. The number of institutions for each enrollment band is computed using just enrollments for the relevant educational type (online or in-person). The columns titled "Avg. \% nonresident" contain the mean share of enrolled students that are nonresidents for institutions that are in the relevant enrollment band

large as the mean enrollment for publics and six times as large as the mean enrollment for private nonprofits. The median online enrollment at for-profits, however, is well below the median at public institutions, so when not operating at large scales, for-profit institutions are more likely to operate small, rather than moderately sized, online programs. ${ }^{23}$

The in-person enrollment patterns reported in Table 5 paint a very different portrait of differences across sectors. Large numbers of institutions from each sector have entered the in-person market, and for-profit institutions disproportionately operate at small scales. Because for-profit institutions are more likely to select those activities that best produce profits, these differences by sector suggest that a large number of local small-scale profitable opportunities exist for in-person education, while a small number of large-scale nationally-oriented profitable opportunities are present for online education.

\section{Spending on Endogenous Fixed Costs}

Sutton's model has implications for expenditure patterns as well as enrollment patterns, because the model implies that expenditures on endogenous fixed costs by leading online institutions will increase as the size of the online market grows over time. Up to this point, we have solely focused our attention on enrollment patterns because the

\footnotetext{
${ }^{23}$ Private nonprofit institutions also provide a distinct case in regard to scale. Private nonprofits are the most likely to operate at very small scale as their median online enrollment lags well behind the corresponding figure in the other two sectors. They are also the most likely to operate at the very highest scales as three of the five largest online providers are in the private nonprofit sector.
} 
Table 5 Market entry and enrollment size by institutional control, Fall 2018

\begin{tabular}{|c|c|c|c|c|c|c|}
\hline & \multicolumn{2}{|c|}{ Market entry } & \multicolumn{4}{|c|}{$\begin{array}{l}\text { Enrollment size (for Institutions with Enroll- } \\
\text { ment }>0 \text { ) }\end{array}$} \\
\hline & \# IHEs & $\%$ Enr $>0$ & Mean & Median & $\% \geq 5000$ & $\%>2000$ \\
\hline \multicolumn{7}{|l|}{ Online } \\
\hline For-profit (All) & 1691 & 9.2 & 3683 & 198 & 12.3 & 16.8 \\
\hline Public (All) & 1828 & 80.9 & 1223 & 637 & 3.0 & 15.7 \\
\hline Private NP (All) & 1643 & 57.3 & 881 & 142 & 2.4 & 5.8 \\
\hline For-profit (4-year) & 198 & 53.0 & 5319 & 490 & 18.1 & 23.8 \\
\hline Public (4-year) & 675 & 94.8 & 1628 & 866 & 4.7 & 22.0 \\
\hline Private NP (4-year) & 1478 & 62.1 & 881 & 147 & 2.4 & 5.9 \\
\hline \multicolumn{7}{|l|}{ In-person } \\
\hline For-profit (all) & 1691 & 98.5 & 362 & 115 & 1.1 & 3.1 \\
\hline Public (all) & 1828 & 99.8 & 7021 & 3557 & 40.7 & 64.6 \\
\hline Private NP (all) & 1643 & 99.1 & 1987 & 939 & 8.3 & 28.7 \\
\hline For-profit (4-year) & 198 & 89.9 & 1293 & 427 & 7.3 & 17.4 \\
\hline Public (4-year) & 675 & 99.7 & 11,848 & 7493 & 63.6 & 86.5 \\
\hline Private NP (4-year) & 1478 & 99.1 & 2187 & 1120 & 9.3 & 31.9 \\
\hline
\end{tabular}

The data source is the IPEDS Fall Enrollment survey. The first two columns of results are based on the full set of institutions for each institutional type. The last four columns of results are based on the set of institutions for each institutional type with positive enrollments for the relevant educational type. The enrollment statistics are computed using just enrollments for the relevant educational type (online or in-person)

available expenditure data for higher education institutions contain numerous limitations. The IPEDS Finance component does not distinguish between expenditures for online programs and expenditures for in-person programs and does not classify expenditures in a way that allows spending on endogenous fixed costs to be measured. The data submitted by higher education institutions to the Internal Revenue Service and the general public via Form 990 also does not distinguish between online and in-person programs and is only provided by private nonprofit institutions.

Form 990, however, does classify expenditures in a helpful manner, because it requires schools to report their level of advertising and promotion expenditures. Advertising is one of the primary examples, along with R\&D, used by Sutton (1991) in discussions of endogenous fixed costs. Consequently, Form 990 data can provide insight, albeit limited, into whether or not leading national universities increase their spending on endogenous fixed costs as market size expands. Increased spending by existing large providers can dissuade other institutions from entering the national market and lead the market for nonresident students to remain concentrated.

Figure 2 reports advertising and promotion expenditures for the four private nonprofit institutions with the largest nonresident online enrollments in the Fall of 2012. Unlike most other online providers in the private nonprofit sector, these schools solely enroll online students (Western Governors University and Excelsior) or primarily enroll online students (Liberty University and Southern New Hampshire). As a group, they captured 50\% of the nonresident online enrollments in the private nonprofit sector in Fall 2012. The expenditure trends in Fig. 2 support Sutton's model in that two of the four institutions invested heavily in advertising and retained, and even grew, their market share. Between the 2012 and 2018 fiscal years, real advertising and promotion expenditures increased by around $180 \%$ 


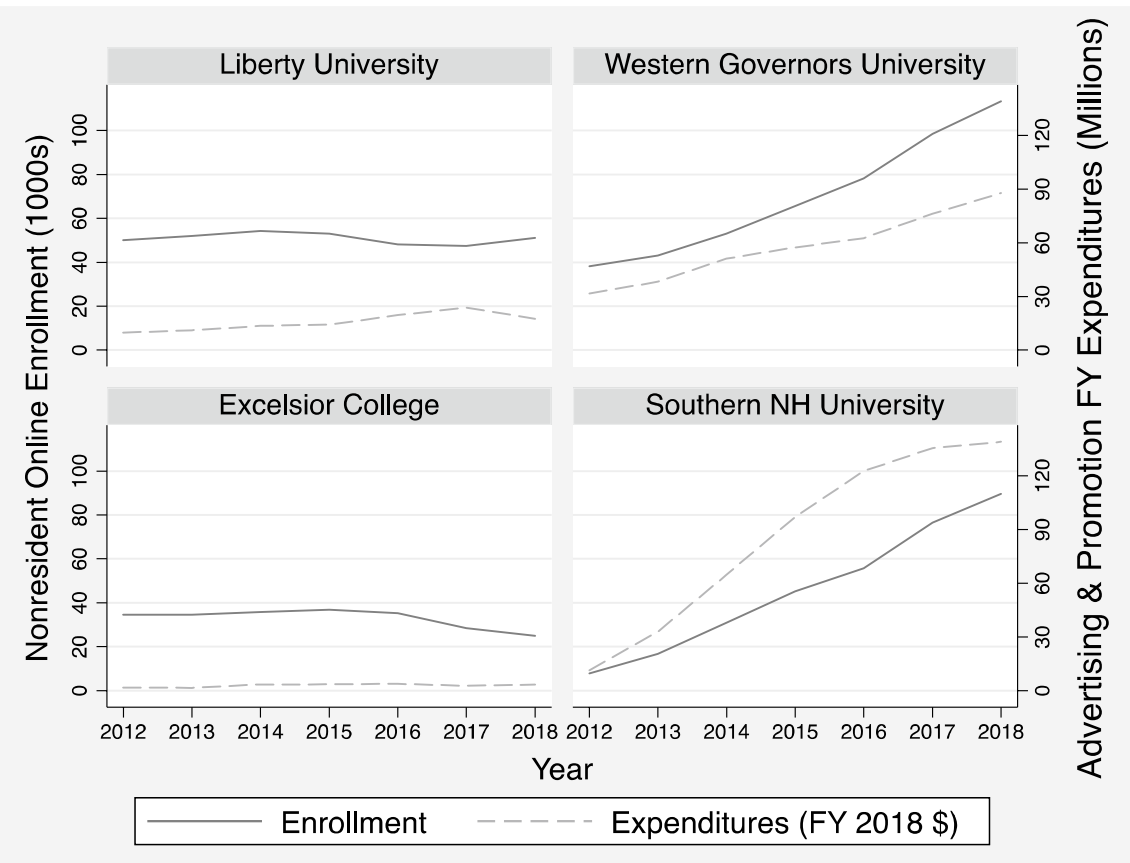

Fig. 2 Nonresident online enrollment and advertising and promotion expenditures for the four largest private nonprofit online providers

at Western Governors University and $1,120 \%$ at Southern New Hampshire University. At the same time, these institutions increased their nonresident online enrollments by $197 \%$ and $1055 \%$.

\section{Discussion}

Sutton's model of endogenous fixed costs suggests that the impact of expanding market size on concentration will depend upon whether a student's valuation of an online program (i.e., quality) is produced primarily through spending on fixed costs or spending on variable costs. If endogenous fixed costs, such as advertising and R\&D, are important determinants of quality, then we should find that concentration levels remain substantial even as market size grows large. The magnitude of these concentration levels may be tempered if horizontal dimensions of quality (e.g., the distance between seller and buyer) are important. If some customers have a preference for nearby organizations, then more organizations will enter the market as small local providers. When applied to online education, this model suggests that the online market will be concentrated and contain a small number of large providers capturing an enduring share of nonresident students and large number of small providers primarily enrolling resident students.

In our empirical analyses, we find that relative to in-person education, national online enrollment patterns are heavily concentrated. The largest ten online providers captured 
around 20-25\% of online enrollment during the Fall of 2018. The scale of these large providers is driven by the enrollment of nonresident students. Over $40 \%$ of online students enroll outside of their home state, and almost half of these nonresident students congregate at 10 large providers. A substantial number of small local providers exist alongside these large national providers.

Overall concentration levels fell between Fall 2012 and Fall 2018 as the enrollments of large for-profit institutions plummeted. Yet substantial levels of concentration remained present in the online market, because concentration levels in the nonprofit sector actually increased over this period. The rise of large nonprofit "mega-universities" (Blumentyk, 2018; Gardner, 2019) meant that overall concentration levels started to plateau, and even slightly rise, by the end of our study period. Data on marketing expenditures by rapidly expanding "mega-universities" match expectations flowing from Sutton's model. In combination, the trends we observe suggest that the national online market may remain fairly concentrated in the decades to come.

Sutton's model enhances our understanding of these patterns and their consequences by highlighting the role of endogenous fixed costs, a type of costs that have received very little attention by higher education researchers. Analysts that ignore these costs will underestimate the organizational costs associated with online education and the level of concentration in online enrollment patterns. Greater attention should be paid to endogenous fixed costs, especially in regard to questions pertaining to magnitude, type, and outsourcing.

The magnitude of endogenous fixed costs that an institution must incur in order to compete in the national market will shape both enrollment patterns and organizational costs. A highly concentrated market with large spending requirements will mean that relatively few higher education institutions will be able to leverage economies of scale and scope to generate substantial positive net tuition revenue. A majority of chief academic officers believe that online education is critical to their institutions' long-term strategy (Allen et al., 2016), so concentrated benefits will heighten the financial sustainability challenges facing many institutions.

The magnitude of spending also carries implications for online students, because it can shape the quality and price of online education. Within the industrial organizational literature from economics, the term quality refers to the valuation of enrollment opportunities by prospective students. These valuations determine the enrollment decisions of these students. We don't yet have a clear sense of how specific types of expenditures (e.g., advertising and recruitment, student services, instruction) shape the valuations of online students. The most influential expenditures will naturally grow in prominence if institutions compete for students by spending on those items that most affect their enrollment decisions.

Higher education researchers are more likely to use the term quality in relation to student learning, development, and outcomes. They will consequently be very interested in whether spending competitions are centered on instruction and student services rather than on advertising and recruitment. We should expect student learning and outcomes to expand more rapidly if institutions compete by focusing further on the development of richly interactive, high-quality online course materials rather than by increasing the level 
of advertising. ${ }^{24}$ If online enrollments continue to grow as expected, the nation's stock of human capital will be increasingly shaped by the nature of online education.

The magnitude and type of spending will influence the decisions of students who are choosing between their local broad access institutions, non-profit mega-universities, and for-profit institutions. Questions about the quality of these educational options relate to important equity concerns about the U.S. higher education system, and Sutton's model highlights specific questions pertaining to educational spending. Investments into the academic quality of online programs at local broad access institutions will be shaped by the number of students enrolling in these programs. Greater attention should be paid to the enrollment preferences of online students (i.e., their preference for local institutions) and the spending on online programs at local broad access institutions. For non-profit mega-universities and for-profit institutions, the most important questions pertain to type of spending rather than magnitude. If these institutions were able to leverage their scale so that they could invest heavily in the quality of their instruction and services, then the enrollment options of geographically constrained students would be greatly enhanced. Limited evidence currently exists on spending patterns. One recent study was conducted by Cellini and Chaudhary (2020) who found higher spending on advertising at for-profit institutions and institutions with greater than $50 \%$ of students taking classes exclusively online.

Endogenous fixed costs create a financing challenge for institutions seeking to create a new online program. An institution must spend heavily during the development and launching of the program, but it does not generate any tuition revenue from the program during these initial periods. To fund this start-up period internally, an institution must either have discretionary resources on hand or take on new debt. A second challenge is that some new online programs are unsuccessful and attract few students, which means the institution will never recoup its initial investment. In response to these and other challenges, nonprofit institutions have been increasingly partnering with for-profit online program managers (OPMs) via tuition share agreements. These agreements provide up-front capital and reduce risk by having the OPM firm cover the initial costs associated with launching an online program and certain ongoing services in return for a share of future tuition revenues. From the perspective of Sutton's model, OPM tuition share-based partnerships transform initial fixed costs into future variable costs and make it easier for an institution to enter the market. Consequently, OPM agreements could potentially decrease the level of concentration in the online market.

The future role of OPMs is uncertain, however. OPM-university partnerships based on tuition share agreements raise policy concerns that might lead to future regulation (Carey, 2019; Hall \& Dudley, 2019). Research into the financing challenge associated with online programs could inform these policy discussions and our understanding of the forces shaping market structure in online education. Such work could also contribute to the literature on academic capitalism (Slaughter \& Leslie, 1997; Slaughter \& Rhoades, 2004), because the use of OPM firms is an advanced form of outsourcing that relates to core activities such as instruction and advising. The embedding of for-profit firms within nonprofit higher education institutions blurs the distinction between nonprofit and for-profit institutions.

\footnotetext{
${ }^{24}$ A less straightforward comparison is between spending on course materials and spending on student services infrastructure. Anecdotal evidence suggests that major online providers view the latter as central. For example, Paul LeBlanc, president of Southern New Hampshire University, regularly states that SNHU wants to have an academic program that is like a Honda Accord and wants to be the Nordstrom of student services (Blumenstyk 2018).
} 


\section{Conclusion}

Our discussion section noted a number of areas for further research relating specifically to endogenous fixed costs, and in this conclusion section, we discuss future research opportunities more broadly. Any discussion of the future must incorporate considerations pertaining to the COVID-19 pandemic, because the widespread use of remote education during the pandemic will likely influence student demand for online education as well as the capacity and desire of higher education institutions to produce online education.

The limited information that exists suggests that student interest in online education grew during the COVID-19 pandemic. Blumenstyk (2021) reported data from the National Student Clearinghouse Research Center indicating that national undergraduate enrollment fell by $4.4 \%$ from fall 2019 to fall 2020 while undergraduate enrollments at predominately online institutions increased by $5 \%$. Similar differences occur when the comparisons are made for graduate students $(+3 \%$ versus $+10 \%)$ and for transfer student $(-8 \%$ versus $+4 \%$ ). Blumenstyk (2021) also noted that enrollments grew rapidly at mega-universities, such as Arizona State $(+20 \%)$, Southern New Hampshire (+18\%), and Western Governors University $(+7 \%)$. This short-term growth in online enrollments likely reflects the low appeal of in-person programs that contain limited and distanced in-person interactions. The long-term post-pandemic impact on student demand will be harder to gauge, because student experiences with remote education could increase or decrease their future interest in online education. ${ }^{25}$ Increased exposure to internet-based learning may make online education more attractive to students, but negative experiences with hastily developed remote learning experiences may produce the opposite effect.

On the supply side, the widespread adoption of remote instruction and student services likely increased the capacity of many institutions to offer fully online programs. The expansion of this capacity could shape the future market structure of online education. If the infrastructure that many institutions developed while providing remote education can be used to increase the number and quality of their online programs in the future, then the pandemic may lead to a narrowing gap between leading national online providers and other institutions. The degree to which institutions can leverage their remote education infrastructure is uncertain, however, because much of that infrastructure was oriented around synchronous instruction and traditionally aged students rather than asynchronous instruction and adult students.

The pandemic may increase higher education institutions' interest in online education, because the pandemic's financial challenges may heighten the need to identify new sources of revenue. Recent evidence suggests that interest in online programs continued to grow during the pandemic. HolonIQ (2021) reported that institutions formed 180 new partnerships with OPM firms in 2020, which is an increase over the previous high of 154 new partnerships in 2019. The rising use of OPM firms may reflect another aspect of the pandemic's financial impact: institutions may find it increasingly difficult to cover start-up costs using internal funds.

\footnotetext{
25 We are using the term remote education to describe the temporary transition of in-person courses and programs to online delivery. The term online education describes courses and programs that were purposely designed for online delivery. In general, we should expect online education to better employ effective online learning design principles than remote education, because institutions have more time and stronger incentives to invest in the development of online courses. Numerous exceptions to the general pattern likely exist, so the distinction between online education and remote education is imprecise.
} 
As further data emerges, researchers can examine how the COVID-19 pandemic impacted market structure in online education. When examining market structure, future work can extend beyond this study to further explore how online enrollment levels relates to the mission, approach, reputation, and other characteristics of higher education institutions. To keep the scope of this study manageable, we only differentiated institutions by institutional control and level. Further differentiation would likely produce additional insight.

Research into differences in online market entry by institutional reputation might be especially important for understanding the future market structure of online education. Institutions with strong existing brands from in-person education have historically shunned online education, but they have shown an increased interest in online education in recent years (McKenzie, 2018). Such schools could potentially leverage their reputations and other resources to gain meaningful levels of market share but may be hesitant to enter the market in a substantive way, as the business model that produced their strong reputation was often based on a scarcity of enrollment slots (Hoxby, 2014). They may choose to enter the market only in targeted fields, a possibility that researchers could study because the IPEDS Completion survey component identifies whether each degree, as measured by the 6-digit Classification of Instructional Programs (CIP) code and award level, is offered as a distance education program. If elite institutions enter the online market in a meaningful way and establish new streams of net revenue, it will further increase the extreme financial inequality that exists across U.S. colleges and universities (Cheslock \& Shamekhi, 2020; Clotfelter, 2017; Taylor \& Cantwell, 2019).

The pricing decisions of online programs is another topic worthy of further study. The largest online nonprofit providers of online education have leveraged economies of scale in order to keep their tuition prices low. Southern New Hampshire University (SNHU) has frozen its online tuition since 2012, and Western Governors University charges a low flat rate for sixmonth terms that does not vary by the number of courses taken.

The limited research that has been conducted on online pricing suggests that these megauniversities are atypical and that nonprofit institutions generally charge similar or higher prices for online than for in-person education once fees are included (Poulin \& Strout, 2017). For institutions with small online enrollments, this pricing may simply reflect the substantial perstudent costs associated with producing online education at a small scale. For institutions with moderate online enrollments, the pricing could be driven by expenditure pressures relating to Sutton's model, because these schools may have spent heavily to attract and retain the students they were able to enroll. Alternatively, the pricing could reflect a desire by institutions to generate large levels of net revenue from online programs. In this latter scenario, online prices (and the institutional net revenue associated with higher prices) might fall over time if competition for online students intensifies. Longitudinal research that examines how online prices relates to competition, scale, organizational characteristics, and other factors could provide helpful insights into the financial impact of online programs on higher education institutions and the nature of the online enrollment choices available to students. If online enrollments continue to grow as expected, the importance of work in this and other areas pertaining to online education will only increase in importance.

\section{Appendix}

See Table 6. 
Table 6 Predicting enrollment in an exclusively online degree program, logit regression

\begin{tabular}{lllr}
\hline & Coeff & Std. err & Z-Stat \\
\hline Online share of institution's students & 2.101 & 0.368 & 5.71 \\
Resident student & -1.038 & 0.193 & -5.37 \\
Private nonprofit, 4-year institution & 0.482 & 0.229 & 2.11 \\
Private for-profit, 4-year institution & 1.049 & 0.281 & 3.73 \\
Public, 2-year institution & -0.585 & 0.144 & -4.06 \\
Private for-profit, 2-year institution & 0.812 & 0.570 & 1.42 \\
Intercept & 1.491 & 0.196 & 7.59 \\
Number of observations & 6,490 & & \\
Pseudo R-squared & 0.2509 & & \\
\hline
\end{tabular}

The data source is NPSAS:12. Only students who report taking all of their courses online during the 2011-2012 academic year were included in the regression. The dependent variable is an indicator for enrollment in an exclusively online degree program. The regression was weighted using the NPSAS variable "wta000"

Acknowledgements The authors wish to thank Bradley Curs, Justin Ortagus, Russ Poulin, Mark Roberts, and Liang Zhang for helpful discussions, Yahya Shamekhi for research assistance, and Crystal Han and Eunjong Ra for editing.

\section{References}

Acemoglu, D., Laibson, D., \& List, J. A. (2014). Equalizing superstars: The Internet and the democratization of education. American Economic Review, 104(5), 523-527.

Allen I. E., Seaman, J., Poulin, R., \& Straut, T. T. (2016). Online report card: Tracking online education in the United States. Babson Survey Research Group.https://onlinelearningsurvey.com/reports/onlinerepo rtcard.pdf

Archibald, R. B., \& Feldman, D. H. (2011). Why does college cost so much? Oxford University Press.

Archibald, R. B., \& Feldman, D. H. (2017). The road ahead for America's colleges and universities. Oxford University Press.

Berry, S., \& Waldfogel, J. (2010). Product quality and market size. The Journal of Industrial Economics, $58(1), 1-31$.

Bettinger, E., Fox, L., Loeb, S., \& Taylor, E. (2015). Changing distributions: How online college classes alter student and professor performance. Working Paper 15-10. Stanford Center for Education Policy Analysis.

Blumenstyk, G. (2018). Meet the new mega-university. The Chronicle of Higher Education. November 11. https://www.chronicle.com/article/Meet-the-New-Mega-University/245049

Blumenstyk, G. (2021). Enrollment may be down, but some established onlie providers are seeing a surge. The Chronicle of Higher Education. January 27. https://www.chronicle.com/newsletter/the-edge/ 2021-01-27

Brinkman, P., \& Leslie, L. (1986). Economies of scale in higher education: Sixty years of research. The Review of Higher Education, 10(1), 1-28.

Carey, K. (2019, April 1). The creeping capitalist takeover of higher education. The Huffington Post. https:// www.huffpost.com/highline/article/capitalist-takeover-college/

Carlson, S. (2014, February 3). Accounting for success. The Chronicle of Higher Education. https://www. chronicle.com/article/accounting-for-success/

Cellini, S. R., \& Chaudary, L. (2020, May 19). Commercials for college? Advertising in higher education. The Brookings Institution. https://www.brookings.edu/research/commercials-for-college-advertisingin-higher-education/

Cellini, S. R., \& Goldin, C. (2014). Does federal student aid raise tuition? New evidence on for-profit colleges. American Economic Journal: Economic Policy, 6(4), 174-206. 
Cellini, S. R., \& Turner, N. (2019). Gainfully employed? Assessing the employment and earnings of forprofit college students using administrative data. Journal of Human Resources, 54(2), 342-370.

Cheslock, J., Ortagus, J., Umbricht, M., \& Wymore, J. (2016). The cost of producing higher education: An exploration of theory, evidence, and institutional policy. In J. Smart (Ed.), Higher education: Handbook of theory and research (Vol. 31, pp. 349-392). Springer.

Cheslock, J., \& Shamekhi, Y. (2020). Decomposing financial inequality across U.S. higher education institutions. Economics of Education Review, 78, 102035.

Christensen, C., \& Eyring, H. J. (2011). The innovative university: Changing the DNA of higher education from the inside out. Jossey-Bass.

Clotfelter, C. T. (2017). Unequal colleges in the age of disparity. Harvard University Press.

Congressional Research Service. (2007, March 9). Institutional eligibility for participation in Title IV student aid programs under the Higher Education Act: Background and reauthorization issues. Accessed from https://www.everycrsreport.com/reports/RL33909.html

Cowen, T., \& Tabarrok, A. (2014). The industrial organization of online education. American Economic Review, 104(5), 519-522.

De Vlieger, P., Jacob, B., \& Stange, K. (2016). Measuring instructor effectiveness in higher education. Working Paper 22998. National Bureau of Economic Research.

Ellickson, P. B. (2007). Does Sutton apply to supermarkets? The RAND Journal of Economics, 38(1), 43-59.

Ellickson, P. B. (2015). Market structure and performance. In J. D. Wright (Ed.), International encyclopedia of the social and behavioral sciences (2nd ed., Vol. 14, pp. 9211-9216). Elsevier.

Fabina, J. (2019). The effect of federal oversight on for-profit colleges. Unpublished manuscript. Boston: Boston University.

Fountain, J. H. (2019). The effect of the gainful employment regulatory uncertainty on student enrollment at for-profit institutions of higher education. Research in Higher Education, 60(1), 1065-1089.

Gardner, L. (2019, February 17). The rise of the mega-university. Chronicle of Higher Education. https:// www.chronicle.com/interactives/Trend19-MegaU-Main

Geiger, R. L. (2015). The history of American higher education: Learning and culture from the founding to World War II. (Vol. 80). Princeton University Press.

Goldin, C., \& Katz, L. F. (1999). The shaping of higher education: The formative years in the United States, 1890 to 1940. Journal of Economic Perspectives, 13(1), 37-62.

Grawe, N. D. (2018). Demographics and the demand for higher education. Johns Hopkins University Press.

Hall, S. \& Dudley, T. (2019). Dear colleges: Take control of your online courses. The Century Foundation. September 12. https://tcf.org/content/report/dear-colleges-take-control-online-courses/

Hannan, M., \& Freeman, J. (1977). The population ecology of organizations. American Journal of Sociology, 82(5), 929-964.

HolonIQ. (2021). 1,377 university partnerships: OPMs, bootcamps, and the academic PPP acceleration. https://www.holoniq.com/notes/1377-university-partnerships.-opms-bootcamps-and-the-academicppp-acceleration./

Hoxby, C. M. (1997). How the changing market structure of U.S. higher education explains college tuition. Working Paper 6323. National Bureau of Economic Research.

Hoxby, C. M. (2009). The changing selectivity of American colleges. Journal of Economic Perspectives, 23(4), 95-118.

Hoxby, C. M. (2014). The economics of online postsecondary education: MOOCs, nonselective education, and highly selective education. American Economic Review, 104(5), 528-533.

Jaquette, O., \& Parra, E. (2016). The problem with the Delta Cost Project database. Research in Higher Education, 57(5), 630-651.

Jones, D. (2004). Technology costing methodology handbook-Version 2.0. Western Cooperative for Educational Telecommunications. https://wcet.wiche.edu/sites/default/files/TCM-Handbook.pdf

Kane, T. J., Orszag, P. R., \& Gunter, D. L. (2003). State fiscal constraints and higher education spending: The role of Medicaid and the business cycle. Urban-Brookings Tax Policy Center. Discussion Paper Number 11.

Kinser, K., \& Zipf, S. T. (2019). Assessing a moving target: Research on for-profit higher education in the United States. In M. B. Paulsen \& L. W. Perna (Eds.), Higher education: Handbook of theory and research (Vol. 34, pp. 325-372). Springer.

Kwoka, J. E., \& Snyder, C. M. (2004). Dynamic adjustment in the U.S. higher education industry, 19551997. Review of Industrial Organization, 24(4), 355-378.

Latcovich, S., \& Smith, H. (2001). Pricing, sunk costs, and market structure online: Evidence from book retailing. Oxford Review of Economic Policy, 17(2), 217-234. 
McKenzie, L. (2018, September 19). An elite online bachelor's degree. InsideHigherEd.com https:// www.insidehighered.com/digital-learning/article/2018/09/19/penn-introduces-new-online-bache lors-degree-program

McKenzie, L. (2019, March 13). UMUC 2.0. InsideHigherEd.com https://www.insidehighered.com/digit al-learning/article/2019/03/13/university-maryland-university-college-will-change-name-and

Meyer, K. A. (2006). Cost-efficiencies in online learning. ASHE Higher Education Report, 32(1), 1-123.

Ortagus, J. C. \& Derreth, R. T. (2020). "Like having a tiger by the tail": A qualitative analysis of the provision of online education in higher education. Teachers College Record.

Ortagus, J. C., \& Yang, L. (2018). An examination of the influence of decreases in state appropriations on online enrollment at public universities. Research in Higher Education, 59(7), 847-865.

Poulin, R., \& Hill, P., (2014). Investigation of IPEDS Distance Education data: System not ready for modern trends. WCET Frontiers. https://wcetfrontiers.org/2014/09/25/ipeds/

Poulin, R., \& Straut, T. (2017). Distance education price and cost report. WCET. https://wcet.wiche. edu/initiatives/research/price-cost-distance-ed

Rumble, G. (1997). The costs and economics of open and distance learning. Kogan Page.

Shaked, A., \& Sutton, J. (1987). Product differentiation and industrial structure. Journal of Industrial Economics, 36(2), 131-146.

Sjogren, J., \& Fay, J. (2002). Cost issues in online learning: Using "co-opetition" to advantage. Change The Magazine of Higher Learning, 34(3), 52-57.

Skinner, B. T. (2019). Making the connection: Broadband access and online course enrollment at public open admissions institutions. Research in Higher Education, 60(7), 960-999.

Slaughter, S., \& Leslie, L. L. (1997). Academic capitalism: Politics, policies, and the entrepreneurial university. The Johns Hopkins University Press.

Slaughter, S., \& Rhoades, G. (2004). Academic capitalism and the new economy: Markets, state, and higher education. The Johns Hopkins University Press.

Smith, D. O. (2020, July 1). How university finances work in a crisis. The Chronicle of Higher Education. https://www.chronicle.com/article/How-University-Finances-Work/249101

Straumshein, C. (2017, February 27). Huge deal for a small school. The Chronicle of Higher Education. https://www.insidehighered.com/news/2017/02/27/how-two-simmons-college-online-programsbecame-multimillion-dollar-venture

Straut, T. T., \& Poulin, R. (2016). Investigating IPEDS Distance Education data reporting: Progress has been made. WCET Frontiers. https://wcetfrontiers.org/2016/04/18/investigating-ipeds-distance-educa tion-data-reporting-progress-has-been-made/

Stripling, J. (2015, February 23). An online kingdom come. The Chronicle of Higher Education. https:// www.chronicle.com/article/an-online-kingdom-come/

Sutton, J. (1991). Sunk cost and market structure: Price competition, advertising, and the evolution of concentration. The Massachusetts Institute of Technology Press.

Sutton, J. (1998). Technology and market structure. The Massachusetts Institute of Technology Press.

Taylor, B. J., \& Cantwell, B. (2019). Unequal higher education: Wealth, status, and student opportunity. Rutgers University Press.

Toutkoushian, R. K., \& Hill, J. C. (2016). Revising economics of scale and scope in higher education. In M. Paulsen (Ed.), Higher education: Handbook of theory and research (Vol. 33, pp. 371-416). Springer.

U.S. Department of Education. (2017). Fall enrollment for 4-year degree-granting institutions 2017-18 survey materials. U.S. Department of Education. https://nces.ed.gov/ipeds/use-the-data/annual-surveyforms-packages-archived

Winston, G. C. (1999). Subsidies, hierarchy and peers: The awkward economics of higher education. Journal of Economic Perspectives, 13(1), 13-36.

Xu, D., \& Xu, Y. (2020). The ambivalence about distance learning in higher education: Challenges, opportunities and policy implications. In L. Perna (Ed.), Higher Education: Handbook of Theory and Research (Vol. 35, pp. 351-402). Springer.

Zemsky, R., Wegner, G., \& Massy, W. (2005). Remaking the university: Market-smart and mission-centered. Rutgers University Press.

Zhang, L., \& Worthington, A. (2018). Explaining estimated economies of scale and scope in higher education: A meta-regression analysis. Research in Higher Education, 59(2), 156-173.

Publisher's Note Springer Nature remains neutral with regard to jurisdictional claims in published maps and institutional affiliations. 